\title{
Salt Tolerance and Screening for Genetic Changes in Rice Mutants after Gamma Irradiation Using RAPD and Microsatellite (RAMP) Markers
}

\author{
T. M. L. Hoang, L. F. De Filippis* and X. T. Le
}

Department of Environmental Sciences, University of Technology, Sydney, P O Box 123, Broadway/Sydney NSW 2007, Australia

\begin{abstract}
Two Vietnamese rice mutants (M2-2 and M2-4 - second generation line 2 and line 4 respectively), induced by gamma irradiation were examined and compared to their parent (TT), and the Australian cultivar Amaroo (Am) for salt tolerance and genomic differences. Seedlings in tissue culture provided high yields and good quality DNA, especially with young shoots. Changes in DNA of the mutants in comparison to TT and Am were successfully assessed using RAPD-PCR (random amplified polymorphic DNA-polymerase chain reaction) and RAMP-PCR (random amplified microsatellite polymorphism-polymerase chain reaction) molecular marker techniques. RAMP-PCR was better than RAPD-PCR at disclosing genetic changes between closely related individuals, and only RAMP-PCR was able to detect polymorphic bands between the two mutants. A measure of heterozygocity and genetic differentiation, the Gstatistic demonstrated that comparisons between Am and TT, M2-2 or M2-4 showed moderate genetic differentiation, but comparisons between TT and M2-2 or M2-4 showed low genetic differentiation. Percentage polymorphism between TT, M2-2, M2-4 and Am detected by RAPD-PCR were similar to those detected by RAMP-PCR (about $10 \%$ ). DNA bands that were polymorphic between the two mutant lines were sequenced, two bands mapped on numerous chromosomes of rice, while two other bands mapped on one or two chromosomes, and these DNA bands on the whole coded for regulatory genes. The results showed that especially RAMP-PCR is a versatile, sensitive and cost effective method for measuring genomic differences between closely related plants.
\end{abstract}

Keywords: Oryza sativa, DNA polymorphism, induced mutations, molecular markers, RAMP-PCR, RAPD-PCR, salt tolerance.

\section{INTRODUCTION}

Spontaneous and induced mutations are the major source of most of the existing genetic variation in plants, and are commonly used in plant breeding. The occurrence of spontaneous mutations in nature is relatively rare and difficult to identify because they can be recessive, or are deleterious and quickly eliminated [1]. Increasing the rate of mutation (ie induced mutations) can provide additional sources of variant genotypes important in plant breeding. Mutagenic agents include alkylating agents, or atomic (X-ray, UV-light) and nuclear (alpha, beta, gamma rays) radiation [2]. Alkylating agents that react with DNA to change nucleotide sequences produce relatively few useful point mutations. However, the absorption of ionising radiation produces more complex DNA and structural chromosomal changes, and are considered the mutagenic agents of choice in plant breeding applications [3].

Mutations can occur in tissue cultured plantlets and the process can be rapid; this process is sometimes called 'somaclonal variation' and these plants have also found value in plant breeding [4]. In recent years the use of tissue culture in

*Address correspondence to this author at the Department of Environmental Sciences, University of Technology, Sydney, P O Box 123, Broadway/Sydney NSW 2007, Australia; Tel: +61-2-9514-4152;

Fax: +61-2-9514-4079; E-mail: lou.defilippis@uts.edu.au combination with radiation induced mutations have resulted in a number of desired genotypes in rice, and a number of these have been used directly or indirectly in breeding programs [5]. However, phenotypic trait selection seldom provide the means for genotypic identification due to environmental and physiological modification of expressed traits, and therefore have limited use for clear genetic identification. Biochemical (e.g. isoenzymes) markers present limitations such as a high bias in genomic sampling, low number of suitable markers, examine minor portions of the genome, and inconsistency between tissue samples cause difficulties in standardisation of methods [6].

Many of the complications of a phenotypic or biochemical based assay can be mitigated through direct identification of genotypes with DNA based assays [7, 8]. One such method is RAPD-PCR (random amplified polymorphic DNA-polymerase chain reaction) which amplifies random genomic DNA sequences using single, short arbitrary primers, and these can be effectively used as genetic markers. The RAPD technique therefore surveys (scans) numerous loci in the genome, which makes this method particularly attractive for analysis of genetic distance and similarity between closely related species $[9,10]$. A recent method to compensate for some weakness in RAPD-PCR such as inconsistency between samples and dominancy of loci targeted has been developed by using combinations of RAPD and microsatellite primers, called RAMP (random amplified microsatellite polymorphism)-PCR [11]. RAMP-PCR has 
crosatellite polymorphism)-PCR [11]. RAMP-PCR has been reported to potentially detect and map co-dominant polymorphisms in DNA without cloning and sequencing, and RAMP-PCR bands were more reliable descriptors of relatedness than RAPD or microsatellite methods by themselves [12]. RAMP-PCR has been reported to be more reproducible and better than RAPD-PCR in disclosing genetic relationship in barley cultivars [13]. The method therefore utilizes the ubiquitous and highly polymorphic nature of microsatellites, with the ease of genome scanning supplied by RAPD primers.

We have previously demonstrated that two second generation M2 selected radiation induced mutants of rice had decreased height and a reduced growing season, but in screening for other traits, these mutants also had altered physiological characteristics [14]. An important difference investigated in this study was the increase tolerance to salt of the second generation mutants. Few studies have compared and estimated genetic changes between the original parental genotype and selected gamma irradiated mutants. Therefore another objective of this study was to compare and quantify the mutagenic effect of gamma irradiation on genetic (DNA) changes in rice using RAPD-PCR and RAMP-PCR, and any relationship to salt tolerance.

\section{MATERIALS AND METHODOLOGY}

\section{Plant Material}

Seeds of rice (Oryza sativa L.) varieties Tam Thom (TT) and Amaroo (Am), and selfed progeny of TT, mutants M2-2 and M2-4 were germinated and maintained on Murashige and Skoog (MS) media supplemented with $2 \mathrm{mg} / \mathrm{L}$ benzylaminopurine (BA) [15] in a plant growth room with a temperature of $252^{\circ} \mathrm{C}$, relative humidity of $85-90 \%$ and day/night cycle of $12 \mathrm{hr}$ at $50 \mu \mathrm{mol} \cdot \mathrm{m}^{-2} \cdot \mathrm{s}^{-1}$ light intensity. For growth determination seeds were germinated in the MS+BA media above supplemented with different levels of $\mathrm{NaCl}(0-$ $200 \mathrm{mM}$ ) for 6 weeks. The induced mutants of TT - the second generation mutant line 2 (M2-2) and the second generation mutant line 4 (M2-4) were derived from exposure of seeds to $200 \mathrm{~Gy}$ from a ${ }^{60} \mathrm{Co}$ gamma irradiation source, and both mutant lines were specifically selected for a shorter growth cycle and reduced height [14].

\section{DNA Extraction and Optimisation of PCR}

Leaf slices (6 weeks old) were frozen in liquid nitrogen, crushed in a microfuge tube with CTAB isolation buffer [2\% w/v cetyltrimethyl ammonium bromide (CTAB), $1.4 \mathrm{M}$ $\mathrm{NaCl}, 1 \% \mathrm{v} / \mathrm{v}$ B-mercapto ethanol (BME), $1 \% \mathrm{w} / \mathrm{v}$ polyvinyl pyrrolidone (PVP), $20 \mathrm{mM}$ EDTA, $100 \mathrm{mM}$ tris(hydroxymethyl) aminomethane (Tris)-HCl, $\mathrm{pH}$ 8.0] [16], and incubated at $60^{\circ} \mathrm{C}$ for $30 \mathrm{~min}$ [17]. Proteinase K (10 $\mathrm{mg} / \mathrm{ml}$ )(Sigma) was added, and incubated for $90 \mathrm{~min}$ at $37^{\circ} \mathrm{C}$. The mixture was extracted with equal volumes of chloroform:isoamylalcohol (24:1), and the nucleic acids precipitated with the addition of $2 / 3$ the volume of isopropanol. The pellet was washed and desalted with chilled $70 \%$ ethanol, air dried, DNA dissolve overnight in TE buffer $(10 \mathrm{mM}$ Tris-HCl, $1 \mathrm{mM}$ EDTA, $\mathrm{pH}$ 8.0), and all DNA preparations were treated with RNase A $(10 \mathrm{mg} / \mathrm{ml})$ (Sigma) for $60 \mathrm{~min}$ at $37^{\circ} \mathrm{C}$ [18]. Concentrations of DNA were estimated using a Pharmacia GeneQuant DNA/RNA calculator, and confirmed after electrophoresis by comparison with a known standard (Lambda Hind III, Promega). The purity of the DNA was estimated by the ratio of absorbance readings at 260:280nm.

Average yields of DNA from 6 weeks old seedling tissue (2.70.3 $\mathrm{mg} \mathrm{DNA} / \mathrm{g}$ fresh weight) were significantly higher than from tissue as little as 1 week older $(1.80 .4 \mathrm{mg}$ DNA/g fresh weight). Younger rice tissue DNA was better quality, with an average 260:280 ratio of 1.89, while that of the older tissue was close to and often above 2. The optimum amount of $\mathrm{MgCl}_{2}$ required in each PCR reaction varied according to particular primer combinations. In our experiments, $2.5 \mathrm{mM}$ $\mathrm{MgCl}_{2}$ was found suitable and produced strong and consistent banding patterns for all RAPD primers. For microsatellite:RAPD combinations (ratio of 2:1) a concentration of 3.0 $\mathrm{mM} \mathrm{MgCl} 2$ was found to be best. 1.0 unit of Taq polymerase was found optimum for the RAPD primers tested, but in contrast, 1.5 units of $T a q$ polymerase was found optimum for RAMP primers. Finally, $50 \mathrm{ng}$ of genomic DNA produced the strongest and most consistent bands in both RAPD-PCR and RAMP-PCR.

\section{RAPD and RAMP Amplification}

PCR was carried out on DNA samples using 20 RAPD primers (A2, A4, A6, A7, A8, A9, B1, B2, B4, B6, B7, B8, B10, D1, D2, D3, D5, D7, D8, D10, Operon Technologies, Kits A, B and D). Of the 20 RAPD primers tested, 16 were chosen for further use in RAMP; the 4 discarded primers (A6, B2, B7, D1) failed to produce clear bands. 32 combinations of two anchored (anchored bases underlined) microsatellite (MS) primers (MS1 - 5'CAACACACACACAC3'; MS2 - 5'TGACACACACACAC3') with the 16 RAPD primers (mol ratio of 2:1 MS to RAPD) were used in RAMP-PCR.

Each reaction was performed in a final volume of $25 \mu \mathrm{L}$ containing $2.5 \mu \mathrm{L}$ 10x Taq Polymerase Reaction Buffer [67 $\mathrm{mM}$ Tris- $\mathrm{HCl}, \mathrm{pH} 8.8,16.6 \mathrm{mM}\left(\mathrm{NH}_{4}\right)_{2} \mathrm{SO}_{4}, 0.45 \%$ (v/v) Triton X-100, $0.2 \mathrm{mg} / \mathrm{ml}$ gelatin] (Biotech), $0.6 \mathrm{M}$ betaine, 2 $\mathrm{mM}$ each of dATP, dTTP, dCTP, dGTP (Biotech), varying amounts of genomic DNA, $\mathrm{MgCl}_{2}$, and Taq DNA polymerase (Biotech), plus 0.5 mM RAPD primer or combinations of one anchored MS and one RAPD primer (1.0 mM MS to $0.5 \mathrm{mM}$ RAPD primer). Amplification reactions were carried out in a Biometra Personal Cycler programmed for: 1 cycle at $94^{\circ} \mathrm{C}$ for $5 \mathrm{~min}$, then $35^{\circ} \mathrm{C}$ for $1 \mathrm{~min}$; followed by $40 \mathrm{cy}-$ cles each consisting of $1 \mathrm{~min}$ at $94^{\circ} \mathrm{C}, 1 \mathrm{~min}$ at $36^{\circ} \mathrm{C}$, and $2 \mathrm{~min}$ at $72^{\circ} \mathrm{C}$. Amplified DNA fragments were separated at 100 volts in $2 \%$ agarose gels with TBE buffer $(89 \mathrm{mM}$ Tris, $89 \mathrm{mM}$ boric acid, $2 \mathrm{mM}$ EDTA, $\mathrm{pH} 8.0$ ), and stained for DNA with ethidium bromide $(10 \mathrm{mg} / \mathrm{mL})$. The gels were then viewed on a Uvitec Transilluminator (M020616, Integrated Sciences) and photographed using a Kodak camera (EDAS 290).

\section{Cloning and Sequencing of DNA}

Single DNA bands were excised directly from agarose gels [19]. Ligation and transformation were performed using the pGEM-T plasmid vector system and E.coli JM109 competent cells as per instructions by Promega. Plasmid DNA purification was carried out using the Wizard Plus Miniprep purification system (Promega). DNA was sequenced (using dye-terminator sequencing) in the forward and reverse direc- 
tions by Macquarie University DNA Sequencing Centre using the Perkin Elmer ABI PRISM 377. Recombinant plasmid DNA was sequenced using the pGEM forward $\left(5^{\prime} \mathrm{CCC}\right.$ ACGTCGCATGCTCC3') and reverse (5'CTCCCATATGGTCGACCTG3') primers. Sequences were substituted into a computer databank Basic Local Alignment Search Tool (BLAST) [20] to search for sequence homology in both the general nucleotide databank, and the rice databank of GenBank (at www.ncbi.nlm.nih.gov/BLAST) [21].

\section{Data Analysis}

The results of growth and salt application data were evaluated by analysis of variance (ANOVA). Means that differed significantly were identified using Tukeys HSD test at significance level of $\mathrm{P}<0.05$ using the SPSS statistical package.

Each reproducible PCR band was visually scored ' 1 ' for the presence and ' 0 ' for the absence of bands, and the binary data used for statistical analysis. The band sizes were determined by comparison with a 100 bp DNA molecular weight ladder (Promega), and faint bands of doubtful reproducibility were ignored. Data was analysed with PopGen Version 1.31 [22] and PRIMER Version 5.2.7 [23]. G-statistic $\left(\mathrm{G}_{\mathrm{st}}\right)$, multi dimensional scaling (MDS) and cluster analysis were used to estimate genetic differences between the cultivars and mutants. The G-statistic estimates genetic differentiation and reduction in the number of heterozygote loci based on Nei's regular and unbiased genetic measures [22]. MDS was used to understand patterns of variation within and amongst cultivars and mutants by converting a set of variables into a few dimensions so that individual variations are condensed into a set of limited axes. Such graphical analysis helped to identify the individuals and primers which tend to cluster together (or apart). Cluster procedure was an average linking one, and all similarities used were Bray-Curtis to produce dendrograms [23].

\section{RESULTS}

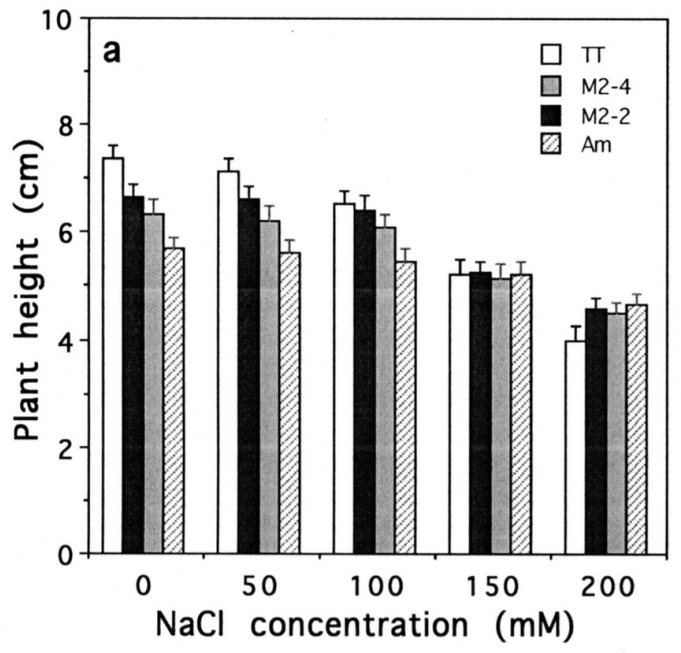

\section{Growth and Salinity}

In tissue culture the parent rice cultivar (TT) was significantly longer in plant height than the mutant lines (M2-2 and M2-4) and Amaroo (Am). $\mathrm{NaCl}$ exposure caused the length of the developing rice shoot to decrease in all cultivars and mutant lines (ANOVA F=13.40, $\mathrm{P}=0.003$ ). Tukeys HSD demonstrated a slight decrease in plant height in TT at 100 $\mathrm{mM} \mathrm{NaCl}(\mathrm{P}=0.041)$, while in the mutant lines and $\mathrm{Am}$, $\mathrm{NaCl}$ significantly decreased shoot length at $150 \mathrm{mM}$ (Tukeys HSD, $\mathrm{P}=0.012$ ) (Fig. 1a). The number of roots formed was generally a more sensitive indicator of salt exposure than plant height in culture (ANOVA $\mathrm{F}=19.42$, $\mathrm{P}=0.001)$. In TT and mutant lines a lowering in number of roots was evident at $100 \mathrm{mM} \mathrm{NaCl}$, and this was significant according to Tukeys HSD ( $\mathrm{P}=0.028,0.037)$, with the exception of Am ( $\mathrm{P}=0.069)$ where there was no significant decrease in root number (Fig. 1b).

\section{RAPD-PCR}

The total number and number of polymorphic bands generated by RAPD primers in TT, M2-2, M2-4 and Am is given in Table 1. All of the RAPD primers tested in this study produced a very similar pattern of bands in TT, M2-2 and M2-4 as shown with primer D8 in Fig. (2a). However some primers generated more bands in TT, M2-2 and M2-4 than in Am, and vice versa. There were few band differences detected in comparison between TT, M2-2 and M2-4 by RAPD-PCR. In other words, very few polymorphisms were detected between TT and its two mutants. As might be expected polymorphisms between Am and TT, M2-2 or M2-4 were about $10 \%$ (Table $\mathbf{1}$ ).

MDS showed differences between groups of primers in detecting polymorphic bands between the cultivars and mutants tested (Fig. 3a). Primers A2, B8, D2, and D5 were grouped together as they were able to generate polymorphic bands in Am that were missing in TT, M2-2 and M2-4. Another grouping consisted of primers able to detect polymor-

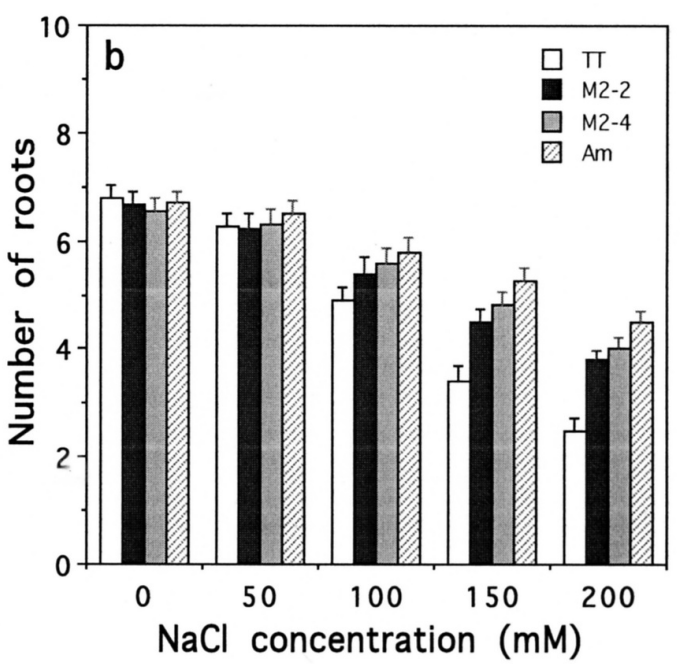

Fig. (1). (a) Plant height and (b) Number of roots in rice cultivars and mutants germinated in tissue culture and then exposed to various concentrations of $\mathrm{NaCl}$ over a period of 6 weeks. Data are the means $(\mathrm{n}=20)$ at the end of 6 weeks of growth in tissue culture, with vertical bars representing standard errors of the mean. 
Table 1. DNA Polymorphism and Genetic Differentiation in Pairwise Comparisons Between Am, TT, M2-2, and M2-4 as Detected by RAPD-PCR. Results were from Duplicate PCR Reactions, where Only Consistent Reproducible Bands were Included from 20 RAPD Primers. G-Statistic is Identical to the F-Statistic where Only Two Possible Alleles are Scored at Any Locus, or where Analysis of Presence or Absence of Bands is Conducted. G-Statistic However does not Require Knowledge of Genotype Frequencies, and is a Measure of the Reduction in the Numbers of Heterozygote Loci and Genetic Differentiation

\begin{tabular}{|c|c|c|c|c|c|c|}
\hline RAPD-PCR & TT / M2-2 & TT / M2-4 & M2-2 / M2-4 & Am / TT & Am / M2-2 & Am / M2-4 \\
\hline \hline Total number bands scored & 221 & 221 & 221 & 225 & 225 & 225 \\
\hline Number of polymorphic bands & 3 & 2 & 1 & 23 & 25 & 26 \\
\hline Percentage polymorphism & 1.36 & 0.90 & 0.45 & 0.20 & 11.11 & 11.56 \\
\hline G-statistic $\left(\mathrm{G}_{\mathrm{st}}\right)$ & 0.04 & 0.03 & 0.02 & 0.11 & 0.12 & 0.13 \\
\hline
\end{tabular}

phic bands present in TT, M2-2 and M2-4 but missing in Am (A8, A9, B4, B6, D3, D7, and D10). The rest of the primers detected no differences between TT, M2-2, M2-4 and Am. The average linkage dendrogram derived from similarity percentages in rice cultivars and mutants by RAPD-PCR is shown in Fig. (4a).

\section{RAMP-PCR}

The total number and number of polymorphic bands generated by combinations of MS1 and 16 RAPD primers, is shown in Table 2 . The combination of MS1 and RAPD primers produced more bands per fingerprint in TT, M2-2, M2-4 and Am than the respective RAPD primers alone. Am generated more bands than TT, M2-2 and M2-4 in all combinations of RAMP primers tested (Table 2). However using MS1 produced low numbers of polymorphic bands in comparison of TT with mutants M2-2 and M2-4. MDS and the dendrogram of RAMP-PCR using MS1 demonstrated a simi- lar relationship between Am, TT1, M2-2 and M2-4 as RAPD-PCR (data not shown).

Combinations of MS2 and 16 RAPD primers produced fewer bands overall than combinations of MS1 and RAPD primers, and not as many low molecular weight bands as did combinations of MS1 and RAPD primers, or RAPD primers alone (Table 2). Nevertheless using MS2 produced more polymorphic bands in comparison of TT with M2-2 and M24 than using MS1. MDS analysis showed that MS2+B1, $\mathrm{MS} 2+\mathrm{B} 10, \mathrm{MS} 2+\mathrm{D} 2$ and MS2+D5 combinations were the best in terms of detecting bands that were present in the parent (TT) but absent in the mutant M2-2 and/or M2-4 (Fig. 2b). Combinations of $\mathrm{MS} 2+\mathrm{A} 2, \mathrm{MS} 2+\mathrm{A} 8, \mathrm{MS} 2+\mathrm{B} 4$, and MS2+D3 were able to generate bands that were present in Am but absent in TT, M2-2 and M2-4. Combination of $\mathrm{MS} 2+\mathrm{A} 4$ and MS2+D8 were able to reveal bands that were present in TT, M2-2 and M2-4 but absent in Am (Fig. 3b). The average linkage dendrogram (Fig. 4b) generated by

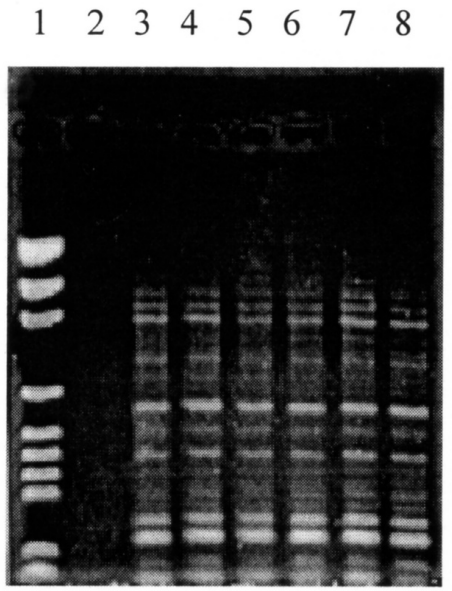

(a) $\begin{array}{llllllll}1 & 2 & 3 & 4 & 5 & 6 & 7 & 8\end{array}$

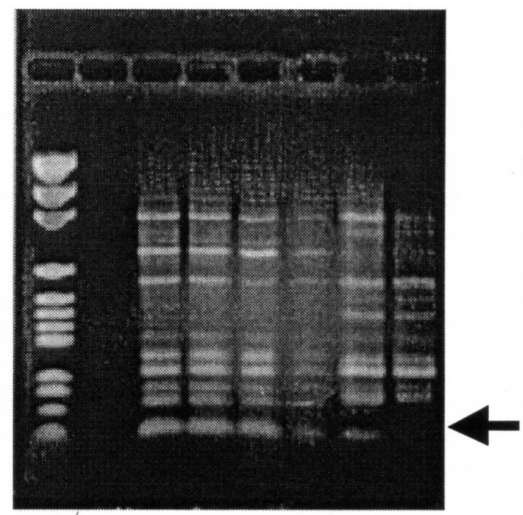

(b)

Fig. (2). (a) RAPD-PCR and (b) RAMP-PCR profiles of DNA from rice cultivars and mutants using (a) RAPD primer D8 or (b) RAMP primer combination MS2+D5. RAPD-PCR and RAMP-PCR reactions were run over 40 cycles using 50 ng genomic DNA, and separated in $2 \%$ agarose. In both gels, lane 1 contained a molecular weight marker (100 bp DNA hyper-ladder I), and lane 2 contained the negative control (all PCR components except genomic DNA). (a) lanes 3-4 = TT; lanes 5-6 = M2-2; lanes 7-8 = M2-4. (b) lanes 3-4 = TT; lanes 5-6 = M2-2; lane 7 = Am; lane $8=$ M2-4. Note the polymorphic band of approximately 700 bp missing in M2-4, which was later sequenced (arrowed). 
A: RAPD-PCR

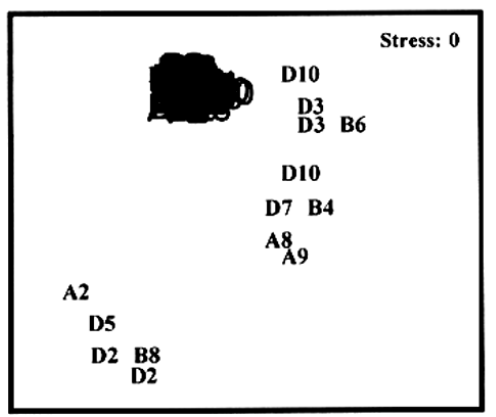

B: RAMP-MS2

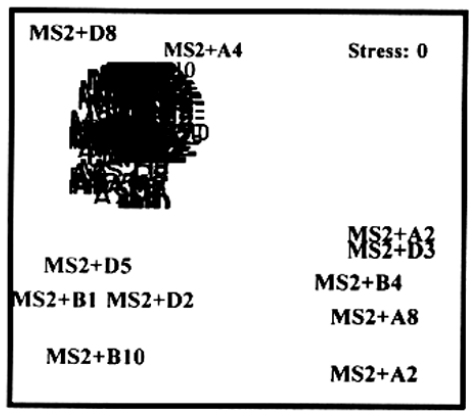

Fig. (3). Multi dimensional scaling (MDS) to illustrate genetic information provided by (a) 20 RAPD primers and (b) combinations of MS2 and 16 RAPD primers for rice cultivars and mutants. Cluster procedure was an average linking one, and all similarities were Bray-Curtis. MDS procedure was non-metric, which means distances between samples on plots were in the same rank order as similarities, as analysed by PRIMER.

MS2 and RAPD primers showed a difference in relationship between TT, M2-2 and M2-4, and appeared more useful than the combination of MS1 and RAPD primers in detecting polymorphisms. Interestingly, RAMP-PCR with both microsatellite primers also detected about $10 \%$ polymorphism between Am and TT, M2-2 and M2-4 (Table 2), the same as RAPD-PCR.

Combinations of MS2 and RAPD primers were able to detect a number of band differences between the parent and mutants (Table 2), but only four strong bands were polymorphic between the two mutant lines (ie the polymorphic band present in Fig. (2b) using MS2+D5 primers). The molecular weight of these bands ranged between $275 \mathrm{bp}$ and $700 \mathrm{bp}$, which is only low to moderate in length. Two DNA bands sequenced (275 and $560 \mathrm{bp}$ ) apparently did not code for traits or genes in the databanks examined, they were identified as just genomic DNA of rice and this feature was confirmed by only a small fraction of the DNA (max. 39\%) mapping on any one rice chromosome (Table 3). Rather, various segments of each of the DNA sequences mapped on at least 4 or 5 rice chromosomes. One DNA band of $500 \mathrm{bp}$ was $84-89 \%$ homologous to the mRNA for sadenosylmethionine decarboxylase from Malus $X$ domestica, Citrofortunella mitis and Lotus corniculatus. This DNA band predominantly mapped on chromosomes 3 and 5 of the rice genome (Table 3 ). The final DNA band sequenced of

\section{A: RAPD-PCR}

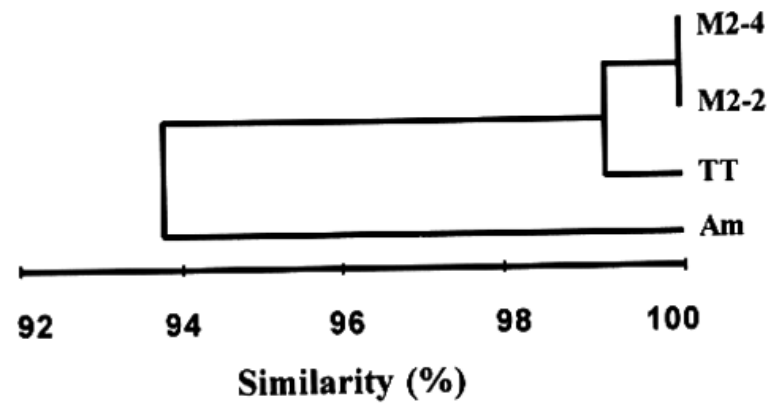

$700 \mathrm{bp}$ was more informative in that it was $78-97 \%$ homologous with the mRNA for fructose bisphosphate aldolase of Arabidopsis thaliana and Pisum sativum. It was also homologous to the BARE-1 long terminal repeat DNA of Hordeum vulgare $(85 \%)$. In rice this sequence was $80-84 \%$ homologous to the mRNA for aldolase C-1, fructose bisphosphate aldolase and a gene for cytoplasmic aldolase; the DNA fragment mapping predominantly on chromosomes 11 of rice (Table $\mathbf{3}$ ).

\section{DISCUSSION}

It was evident from the growth test and salt exposure that the parent cultivar TT was the most salt sensitive. The two mutant lines selected and stabilized were found to have more tolerance to salt, however salt tolerance was found to be highest in the Australian cultivar Amaroo; which is considered only moderately tolerant to salt. Molecular analysis showed that the RAPD and RAMP primers tested had different requirement for $\mathrm{Mg}^{2+}$, where the combination of a microsatellite and a RAPD primer required higher amounts of $\mathrm{Mg}^{2+}$. These results appear to agree with observations that the optimum concentration of $\mathrm{Mg}^{2+}$ for PCR is dependent on the specific sequence of primers used [24]; and also supports the suggestion that multiplex PCR reactions (using two or more primers together) require more $\mathrm{Mg}^{2+}$ than single primer reactions [25]. Not surprising then, RAMP-PCR also ap-

\section{$B: R A M P-M S 2$}

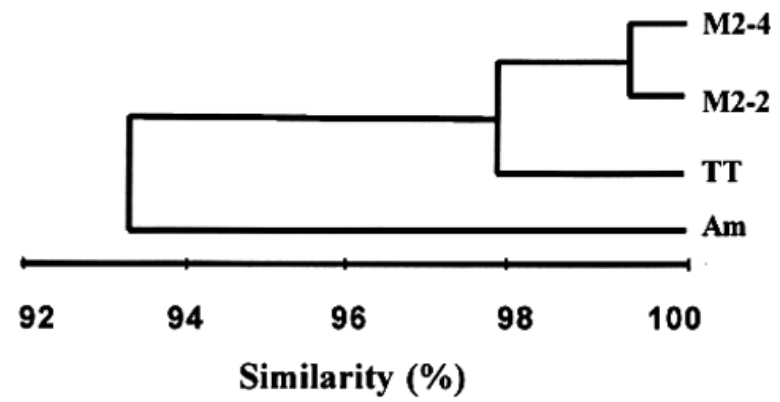

Fig. (4). Average linkage dendrogram to illustrate genetic relationship between rice cultivars and mutants in analysis by (a) RAPD-PCR and (b) RAMP-PCR with MS2. All similarities used were Bray-Curtis and cluster analysis was used to estimate differences between cultivars and mutants in PRIMER. Results were determined from data where between 152 and 241 bands in total were scored, and percent similarities averaged. 
Table 2. DNA Polymorphism and Genetic Differentiation in Pairwise Comparisons Between Am, TT, M2-2, and M2-4 as Detected by RAMP-PCR. Results were from Duplicate PCR Reactions, where Only Consistent Reproducible Bands were Included from Combinations of One of the Two MS Primers with 16 RAPD Primers. G-Statistic is Identical to the F-Statistic where Only Two Possible Alleles are Scored at Any Locus, or where Analysis of Presence or Absence of Bands is Conducted. G-Statistic However does not Require Knowledge of Genotype Frequencies, and is a Measure of the Reduction in the Numbers of Heterozygote Loci and Genetic Differentiation

\begin{tabular}{|c|c|c|c|c|c|c|}
\hline Total number bands scored & 233 & 233 & 233 & 241 & 241 & 241 \\
\hline Percentage polymorphism & 1.29 & 1.72 & 1.29 & 11.20 & 10.79 & 9.54 \\
\hline Total number bands scored & 152 & 152 & 152 & 160 & 160 & 160 \\
\hline Number of polymorphic bands & 8 & 7 & 5 & 19 & 18 & 20 \\
\hline Percentage polymorphism & 3.29 & 4.61 & 3.29 & 11.88 & 11.25 & 12.50 \\
\hline
\end{tabular}

peared to require higher amounts of Taq polymerase, consistent with these observations.

\section{RAPD-PCR Screening}

RAPD-PCR is a simple technique that can be applied where no knowledge of the target DNA is available. The random nature of the primers primarily target small inverted repeats in DNA imperfectly complementary to primers. Amplification differences (i.e. absence or presence of a band) can be the result of base substitution, base deletion or base insertion; a situation suitable in detecting possible mutation sites. No information about the region amplified is possible with RAPD-PCR, but it is likely that middle or highly repeti- tive DNA is primarily targeted [9]. The ease of using RAPD markers make it a very popular method, and RAPD-PCR has been used for a variety of purposes in plant genetic analysis, although care must be taken with reproducibility [26].

The results in rice from this study suggest that RAPDPCR was able to identify genetic differences between more distantly related rice cultivars [5], and this has also been reported for other plants $[27,28]$. These results must be considered and evaluated with some caution since the nature of the RAPD-PCR method means that normally it over estimates genetic differences. In this study, RAPD-PCR was able to detect only two polymorphic band differences between the parent (TT) and the two mutants (M2-2 and M2-

Table 3. Results from Sequencing Data of DNA Polymorphic Bands Between M2-2 and M2-4 as Detected by RAMP-PCR with MS2. DNA was Sequenced Using the pGEM Forward and Reverse Primers. Sequences were Substituted into a Computer Databank Basic Local Alignment Search Tool (BLAST) to Search for Sequence Homology in Both the General Nucleotide Databank, and the Rice Databank of GenBank (at www.ncbi.nlm.nih.gov/BLAST)

\begin{tabular}{|c|c|c|c|c|c|}
\hline B4 & 275 & 30619 & rice genomic DNA predominantly & 3.3 & gi/29335805 \\
\hline B1 & 500 & 31623 & mRNA for s-adenosylmethionine & $2 \mathrm{e}-09$ & gi $/ 32879790$ \\
\hline \multirow[t]{2}{*}{ A7 } & 560 & 47877 & rice genomic DNA predominantly & 2.6 & gi/20279375 \\
\hline & & & located on chromosomes 1,3 and 4 & & \\
\hline D5 & 700 & 33485 & mRNA for fructose bisphosphate & $1 \mathrm{e}-38$ & gi/25082930 \\
\hline
\end{tabular}


4). A plausible reason for the low degree of polymorphism detected by RAPD is that RAPD markers are usually genetically dominant [11] and the degree of polymorphism detected as a result can be low. It is also possible that the agarose gel electrophoresis and ethidium bromide staining used in this study lacked sufficient sensitivity, and polyacrylamide gels coupled with silver staining with higher sensitivity may detect more polymorphisms [17, 29].

\section{RAMP-PCR Screening}

RAMP-PCR also requires no prior knowledge of the target DNA, and specific microsatellite primers are not needed for species or cultivars tested. Microsatellite makers are codominant and very informative, but in RAMP-PCR it is not known if the polymorphic bands generated were dominant or co-dominant. Both microsatellite and RAMP markers have a high degree of stability and reproducibility compared to RAPD markers [30, 31]. Comparison of MS1 and MS2 with slightly different anchored bases demonstrated that each had different abilities to target sites on DNA. It is likely that the ability of a microsatellite to amplify a sequence in target DNA may also depend on how abundant the microsatellite is in that sequence. Differences in the frequency of repetition of dinucleotide microsatellites have been reported in rice [32].

There is evidence in the literature that RAMP, and other multi-locus microsatellite-fingerprinting methods, capture only some of the polymorphisms associated with microsatellites [33]. The results of MDS analysis showed that RAMP was able to generate some polymorphic bands that RAPD primers alone were not. However, RAMP primers also detected polymorphic bands that were detected by RAPD primers only. RAMP-PCR therefore may not just capture polymorphisms associated with microsatellites [34], but may also detect polymorphisms targeted by the RAPD primers. Polymorphic bands may or may not code for structural genes and this was clearly demonstrated by sequencing some of these bands. Two such band differences between the mutant lines, when sequenced appeared to map on numerous rice chromosomes, these had little homology to known genes in available databanks and revealed little information. However, two other polymorphic bands between the mutant lines were more informative and appeared to code for known regulatory enzymes. These latter two bands were mapped on only one or two chromosomes of rice. As a result nucleotide sequence information will enable the development of DNA specific genetic markers by designing custom made longer PCR primers to these fragments of DNA.

\section{Genetic Variation}

Our results indicated that RAMP-PCR was better than RAPD-PCR at disclosing genetic changes between rice cultivars that were very closely related. The G-statistic demonstrated this best in that with RAPD-PCR, comparisons between Am and TT, M2-2 or M2-4 showed moderate genetic differentiation (value 0.11-0.13), but comparisons between TT and M2-2 or M2-4 showed very low genetic differentiation (value 0.03-0.04). RAMP-PCR with MS2, on the other hand, in comparisons between TT and M2-2 or M2-4 showed a low level of genetic differentiation (value 0.040.06), and comparisons between Am and TT, M2-2 or M2-4 still showed moderate genetic differentiation (value 0.13 0.15). Similarities detected between cultivars in this study were high and suggested that differences between the rice cultivars and mutants were at the level of near 'clonal material'. Even the similarity between the Australian cultivar Amaroo and the Vietnamese cultivar and mutants was high, and probably higher than expected for most cultivars [18].

It is also worth point out that molecular screening is going to examine only a portion of the genome. Many deleterious mutations after gamma irradiation, for example, had been eliminated during earlier generation selection in the mutant lines, and this was unrelated to the radiation dose used; which was in the mid threshold value for rice. Therefore it was not surprising to detect low amounts of genetic changes, and most of the differences detected were in regulatory genes. However, the data demonstrated that massive deletions and rearrangement of chromosomes were not present in the selected mutant lines; a successful outcome for mutation breeding. The study also shows that other physiological/biochemical changes can be present in selected mutant lines, even if not specifically selected for. Therefore it is worthwhile screening for additional altered physiological characteristics in chosen mutant lines of plants, provided that they still fulfill the agronomic characteristics desired.

\section{ACKNOWLEDGMENT}

This work was supported by an AusAID scholarship awarded to TML Hoang.

\section{REFERENCES}

[1] Wada H, Koshiba T, Matsui T, Sato M. Involment of peroxidase in differential sensitivity to -radiation in seedlings of two Nicotiana species. Plant Sci 1998; 132: 109-19.

[2] Arnold NP, Barthakur NN, Tanguay M. Mutagenic effects of acute irradiation on miniature roses: Target theory approach. Hortic Sci 1998; 33: 127-9.

[3] Inukai Y, Miwa M, Nagato Y, Kitano H, Yamauchi A. Characterization of rice mutants deficient in the formation of crown roots Breed Sci 2001; 51: 123-9.

[4] Lee SH, Shon YG, Kim CY, et al. Variations in the morphology of rice plants regenerated from protoplasts using different culture procedures - protoclonal variation of protoplast-derived rice plants. Plant Cell Tissue Organ Cult 1999; 56: 179-87.

[5] Chatterjee B, Dasgupta P. Induction of somaclonal variation by tissue culture and cytogenetic analysis in Oryza sativa L. Biol Plant 1998; 40: 25-32.

[6] Lee SW, Ledig FT, Johnson DR. Genetic variation at allozyme and RAPD markers in Pinus longaeva (Pinaceae) of the white mountains, California. Am J Bot 2002; 89: 566-77.

[7] Micheli MR, Bova R. Fingerprinting Methods based on Arbitrary Primed PCR. Berlin, Germany: Springer-Verlag 1997.

[8] Mengoni A, Gori A, Bazzicalupo M. Use of RAPD and microsatellite (SSR) variation to assess genetic relationships among populations of tetraploid alfalfa, Medicago sativa. Plant Breed 2000; 119 311-17.

[9] Persson HA, Gustavsson BA. The extent of clonality and genetic diversity in lingonberry (Vaccinium vitis-ideae L) revealed by RAPDs and leaf-shape analysis. Mol Ecol 2001; 10: 1385-97.

[10] Crockett PA, Singh MB, Lee CK, Bhalla BL. Genetic purity analysis of hybrid broccoli (Brassica oleracea var. italica) seeds using RAPD PCR. Aust J Agric Res 2002; 53: 51-4.

[11] Wu KS, Tanksley SD. Abundance, polymorphism and genetic mapping of microsatellites in rice. Mol Gen Genet 1993; 241: 225 35.

[12] Panaud O, Chen X, McCouch SR. Development of microsatellite markers and characterization of simple sequence length polymorphism (SSLP) in rice (Oryza sativa L). Mol Gen Genet 1996; 252: 597-607. 
[13] Sanchez de la Hoz MP, Davila JA, Loarce Y, Ferrer E. Simple sequence repeat primers used in polymerase chain reaction amplifications to study genetic diversity in barley. Genome 1996; 39: 1127.

[14] Le XT, Hoang TML, Le TD, et al. Improvement of aromatic rice cultivars by gamma radiation-induced mutation techniques. Annual Report. Ho Chi Minh City, Vietnam: Center for Nuclear Techniques 2001 .

[15] Murashige T, Skoog F. A revised medium for rapid growth and bioassay with tobacco tissue culture. Physiol Plant 1962; 15: 47397.

[16] Murray MG, Thompson WF. Rapid isolation of high molecular weight plant DNA. Nucleic Acids Res 1980; 8: 4321-5.

[17] Magel E, Hauch S, De Filippis LF. Random amplification of polymorphic DNA and reverse transcription polymerase chain reaction of RNA in studies of sapwood and heartwood. In: Chaffey N, Ed. Wood Formation in Trees. Malaysia: Harwood Academic Press 2002.

[18] De Filippis L, Hoffmann E, Hampp R. Identification of somatic hybrids of tobacco generated by electrofusion and culture of protoplasts using RAPD-PCR. Plant Sci 1996; 121: 39-46.

[19] Sambrook J, Russell DW. Molecular cloning: a Laboratory Manual. New York: Cold Spring Harbour Laboratory Press 2001.

[20] Altschul SF, Gish W, Miller W, Myers EW, Lipman DJ. Basic alignment search tool. J Mol Biol 1990; 215: 403-10.

[21] Benson DA, Karsh-Mizrachi I, Lipman DJ, Ostell J, Rapp BA, Wheeler DL. GenBank. Nucleic Acids Res 2000; 28: 15-8.

[22] Yeh FC, Yang RC, Boyle T. Popgene version 1.31. Microsoft window-based freeware for population genetic analysis-quick user guide. Alberta, Canada: Centre for International Forestry Research, University of Alberta 1999.

[23] Clark KR, Gorley RN. Primer version 5.2.7. User manual/tutorial. United Kingdom: Plymouth Marine Laboratory, PRIMER-E Ltd. 2001.
[24] Park YH, Kohel RJ. Effect of concentration of $\mathrm{MgCl}_{2}$ on random amplified DNA polymorphism. Bio Tech 1994; 16: 652-3.

[25] Swanson D. PCR optimization: building the perfect beast. Scientist 1999;13: 26-30.

[26] Esselman EJ, Crawford DJ, Brauner S, Stuessy TF, Anderson GJ, Silva OM. RAPD marker diversity within and divergence among species of Dendroseris (Asteraceae;Lactuceae). Am J Bot 2000; 87: 591-6.

[27] Cabrita LF, Aksoy U, Hepaksoy S, Leitao JM. Sustainability of isozyme, RAPD and AFLP markers to assess genetic differences and relatedness among fig (Ficus carica L) clones. Sci Hortic 2001; 87: 261-73.

[28] Linos AA, Bebeli PJ, Kaltsikes PJ. Cultivar identification in upland cotton using RAPD markers. Aust J Agric Res 2002; 53; 637-42.

[29] Bassam BJ, Caetano-Anolles G, Gresshoff PM. Fast and sensitive silver staining of DNA in polyacrylamide gels. Anal Biochem 1991; 196: 80-3.

[30] Nagamitsu T, Ichikawa S, Ozawa M, et al. Microsatellite analysis of the breeding system and seed dispersal in Shorea leprosuls (Dipterocarpaceae). Int J Plant Sci 2001; 162: 155-9.

[31] Rahman MH, Rajora OP. Microsatellite DNA somaclonal variation in micropropagated trembling aspen (Populus tremuloides). Plant Cell Rep 2001; 20: 531-6.

[32] Wu KS, Jones R, Danneberger L, Scolnik PA. Detection of microsatellite polymorphisms without cloning. Nucleic Acids Res 1995; 22: 3257-8.

[33] Hayden MJ, Sharp PJ. Targeted development of informative microsatellite (SSR) markers. Nucleic Acids Res 2001; 29: 44e.

[34] Struss DM. Boritzki M, Karle R, Iezzoni AF. Microsatellite markers differentiate eight Giessen cherry rootstocks. Hortic Sci 2002; 37: 193-2002.

Received: January 20, 2009

Revised: March 17, 2009

Accepted: August 31, 2009

() Hoang et al.; Licensee Bentham Open.

This is an open access article licensed under the terms of the Creative Commons Attribution Non-Commercial License (http://creativecommons.org/licenses/ by-nc/3.0/) which permits unrestricted, non-commercial use, distribution and reproduction in any medium, provided the work is properly cited. 